\title{
Medios de comunicación de los niños: una asignatura pendiente
}

institucional.us.es/ambitos/

\begin{abstract}
Joaquín Sotelo GonzálezUniversidad Complutense de Madrid
joaquin.sotelo@ccinf.ucm.es
\end{abstract}

Miguel Ángel Ruiz DíazUniversidad Autónoma de Madrid

miguel.ruiz@uam.es

Gregorio Aranda Bricio UNICEF España
garanda@unicef.es

Francisco Cabezuelo LorenzoUniversidad de Valladolid

cabezuelo@hmca.uva.es

\section{Resumen}

La Convención sobre los Derechos del Niño recoge en su articulado varias referencias a los derechos de la infancia en relación con los medios de comunicación. El Comité de los Derechos del Niño consagró en 1996 uno de sus debates a la cuestión del niño y los medios de comunicación y planteó que debería

reunirse documentación sobre experiencias prácticas positivas de participación infantil activa en los medios de comunicación para promover la idea de medios de comunicación de los niños. Apenas existe literatura relevante en relación con esa recomendación del Comité de los Derechos del Niño. Nuestro objetivo es contribuir a cubrir ese vacío y recopilar información sobre iniciativas de participación infantil y

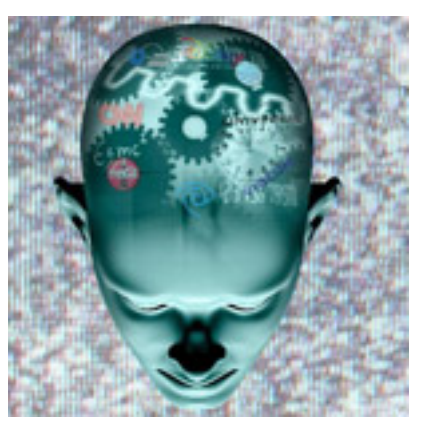

juvenil real y efectiva en la producción de contenidos para medios de comunicación en el ámbito municipal español.

\section{Palabras clave}

Infancia, participación, medios de comunicación, Convención sobre los Derechos del Niño, Comité de los Derechos del Niño.

\begin{abstract}
The Convention on the Rights of the Child includes in his articles several references to the rights of the child in relation to the media. The Committee on the Rights of the Child in a debate in 1996, addressed the issue of children and media, and raised the need to collect documentation on positive real-world experiences of active child participation in the media to promote the idea of media of the children. There is hardly relevant literature in relation to this recommendation of the Committee on the Rights of the Child. Our aim is to bridge that gap and gather information on initiatives for child and youth real and effective participation in producing media content at the Spanish municipal level.
\end{abstract}

\section{Keywords}

Childhood, participation, mass media, Convention on the Rights of the Child, Committee on the Rights of the Child.

\section{INTRODUCCION (1)}

EI Programa Ciudades Amigas de la Infancia (Programa CAI) es una iniciativa de UNICEF España cuyo principal objetivo es impulsar y promover la aplicación de la Convención sobre los Derechos del Niño (CDN) en el ámbito de las Entidades Locales españolas. No obstante, se 
lugar en varios países del mundo.

Uno de los principios básicos de la CDN, y por lo tanto también del Programa CAI, es promover el derecho a la participación ciudadana de toda la infancia en la vida pública, un derecho recogido también explícitamente en la Ley Orgánica 1/1996, de 15 de enero, de Protección Jurídica del Menor (2). En este sentido, los medios de comunicación social presentan un gran potencial como espacio abierto a tal participación. Como ya puso de manifiesto en 2001 el Anuario de Nordicom Outlooks on Children and Media, la participación infantil y juvenil en medios de comunicación genera grandes beneficios para este sector social, porque:

- Refuerza el orgullo y la autoestima de los jóvenes, ya que sienten que sus voces son escuchadas, que son comprendidos y que forman parte activa de su comunidad.

- En su día a día real, sus anhelos y su cultura reflejados en los medios.

- Adquieren nuevos conocimientos (críticos), habilidades y competencias sobre el funcionamiento de los medios.

- Perciben mayor justicia social cuando se les permite acceder a otras formas de expresión, como la producción audiovisual, distintas a las escolares tradicionales.

- Aumenta su interés y su grado de implicación en los asuntos de la comunidad a la que pertenecen y se ven más motivados para mejorar la cobertura mediática de temas con los que se sienten especialmente identificados.

En definitiva, la relación entre medios de comunicación e infancia es importante porque los medios son potentes agentes socializadores; porque la infancia extrae de ellos modelos (tendencias de moda, ídolos, formas de conducta, expresiones, temas de conversación, corrientes de opinión aceptadas o rechazadas...); porque los medios constituyen una ventana al mundo con la que forjarse toda una concepción del mismo y porque son un ámbito más en el que ejercer la libertad de expresión y el derecho a la participación ciudadana. En demasiadas ocasiones, cuando aparecen en los medios, los niños no lo hacen de las formas más adecuadas, o en sus apariciones desempeñan un papel de carácter simbólico, decorativo o, incluso, sesgado, con lo que se crean frecuentemente imágenes públicas distorsionadas o inapropiadas de este colectivo social o se desaprovecha su gran potencial creativo en términos de aportación democrática a su sociedad.

Dentro de la escala de niveles de actividad del niño frente a los medios, existen varios estadios. Martínez de Toda (1998) propone una teoría multidimensional que alberga un proceso en el que el sujeto pasa por diferentes niveles ("alfabetizado", "consciente", "activo", "crítico" y "social") hasta convertirse, de manera integral, en un "sujeto creativo" que pasa a ser productor de contenidos. Carmen Marta Lazo (2005), a propósito de su línea de investigación sobre televisión e infancia, plantea cuatro niveles de actividad del niño frente a este medio: 1) el niño como espectador; 2) el niño como receptor; 3) el niño como perceptor crítico y 4) el niño como perceptor participante. Aunque la profesora de la Universidad de Zaragoza se centra en la televisión, estos niveles podrían ser igualmente aplicables al resto de medios.

En el primero de los estadios aludidos por Marta Lazo, el niño como espectador, éste se limita a establecer un simple proceso de visualización, al igual que puede contemplar un cuadro o una obra teatral, sin llegar a examinar sus significados. Se queda en la forma, sin plantearse los aspectos del contenido. Si nos basamos en el paralelismo entre "ver" y "mirar", podemos afirmar que no mira, sino que solo ve, sin que lo que está viendo llegue a captar plenamente su atención. No obstante, aunque su nivel de actividad sea mínimo respecto a otros ejercicios en los que se implica en mayor medida, no es nulo. Por ello, no podemos hablar de pasividad en sentido absoluto, porque, de hecho, a pesar del reducido nivel de procesamiento de la información que realiza el niño en este estadio, los mensajes dejan su huella (cfr. publicidad o contenidos violentos).

En el segundo escalón, el niño como receptor, éste recibe los mensajes que el emisor le propone, pero continúa sin tener capacidad de interpretarlos con cierto criterio o de leerlos de manera crítica. En este nivel, el niño tan solo elige seguir un medio frente a otras actividades que podría estar realizando, pero no tiene "competencia" (Pérez Tornero, 1994) para argumentar sobre lo que está viendo. Únicamente sabe distinguir entre lo que le 
gusta ver y lo que no, manifiesta sus preferencias y responde con los monosílabos "sí", "no", "mucho", "bastante", "poco" o mediante la simple descripción de lo que mira.

El estadio del niño como perceptor crítico se produce, según Marta Lazo, una vez que el niño recibe el aprendizaje de "educación para los medios", a partir del cual cuenta ya con pautas para analizar la forma y el contenido de los mensajes. Entre otros aspectos, el niño sabrá discernir entre realidad y ficción; dilucidar qué aspectos críticos albergan los contenidos; o extraer los valores y contravalores integrados en las imágenes. Desde la perspectiva de la corriente crítica, se promueve el paso de un destinatario ingenuo ante los mensajes a un perceptor que cuenta con capacidad de elección de contenidos, que intenta comprender los lenguajes mediáticos y sabe interpretar de manera relativamente crítica los significados de los mensajes. Existen varios modelos de educación para los medios que parten precisamente de este enfoque: el de la "educación para la recepción" (Charles y Orozco, 1990), el de la "lectura crítica" (Masterman, 1994) o el "dialéctico-inductivopopular" (Giroux, 1994).En el ámbito de la psicología del aprendizaje, este tercer nivel se correspondería con las teorías cognitivas, que sostienen que las personas somos capaces de realizar elecciones libres en el proceso de aprendizaje (3).

En el último de los estadios identificados por la profesora Marta Lazo, el niño como perceptor participante, éste deja de ser un mero espectador y recorre todos los estadios anteriores: 1) mira la televisión, no se limita a verla como mero espectador; 2) puede describir lo que mira como receptor; 3 ) interpreta la forma y el contenido de los mensajes, porque posee las habilidades necesarias como perceptor crítico y 4) establece comparaciones/relaciones con lo que ya conoce, lo aplica a nuevas situaciones y actúa como perceptor participante. Este perceptor participante, entendido como sujeto social, se reapropia de los significados para llegar a reinterpretarlos, tras un proceso de intercambio de ideas en los distintos contextos en los que se relaciona. En estos contextos de significación (familia, escuela, grupo de pares y medios de comunicación, entre otros) se producen una serie de mediaciones que, unidas a la experiencia previa del niño, le llevan a analizar, reflexionar y aplicar los significados, lo que le dota de un cierto grado de control y autonomía (4). Es en esta cuarta etapa, el niño como perceptor participante, en la que Marta Lazo sitúa la figura del "sujeto creativo" productor de contenidos o "prosumidor" (Toffler, 1980), acrónimo que compendia las iniciales de los términos "productor" y "consumidor" y que alude a que el proceso de percepción lleva al individuo a captar, interpretar y reelaborar todo tipo de información, independientemente del código o sistema expresivo utilizado y de la modalidad de soporte en la que se encuentre.

A la escala de niveles de actividad del niño frente a los medios identificada por Marta Lazo, nosotros añadiríamos un quinto estadio que, en parte y como acabamos de mencionar, la profesora incluye en la fase de "perceptor participante", pero que nosotros proponemos como estadio autónomo: el niño como productor y emisor de mensajes, fase en la que éste asumiría esa función activa de creación y difusión de contenidos. Probablemente, dentro de la literatura científica y de la investigación sobre medios de comunicación e infancia, éste es el estadio menos estudiado. Y es precisamente el punto de la escala en el que circunscribimos nuestra investigación.

La Convención sobre los Derechos del Niño, aprobada por la Organización de las Naciones Unidas en 1989, establece en su artículo 17 que los Estados firmantes, España entre ellos, reconocen el derecho de la infancia al "acceso a la información":

“Los Estados Partes reconocen la importante función que desempeñan los medios de comunicación y velarán por que el niño tenga acceso a información y material procedentes de diversas fuentes nacionales e internacionales, en especial la información y el material que tengan por finalidad promover su bienestar social, espiritual y moral y su salud física y mental".

Y con tal objeto, se añade en el artículo 17, los Estados Partes proponen cinco medidas:

a) alentarán a los medios de comunicación a difundir información y materiales de interés social y cultural para el niño, de conformidad con el espíritu del artículo 29 [de la propia CDN];

b) promoverán la cooperación internacional en la producción, el intercambio y la difusión de esa información y esos materiales procedentes de diversas fuentes culturales, nacionales e internacionales; 
c) alentarán la producción y difusión de libros para niños;

d) alentarán a los medios de comunicación a que tengan particularmente en cuenta las necesidades lingüísticas del niño perteneciente a un grupo minoritario o que sea indígena;

e) promoverán la elaboración de directrices apropiadas para proteger al niño contra toda información y material perjudicial para su bienestar, teniendo en cuenta las disposiciones de los artículos 13 y 18 [de la propia CDN].

Aunque quizá sí la principal, el artículo 17 no es la única referencia en el conjunto del articulado de la CDN al papel que los medios de comunicación deben desempeñar en el proceso de desarrollo de los niños, no solo de los países más avanzados, sino de todo el mundo. A los fines de la presente investigación, nos interesan especialmente las relaciones del artículo 17 de la CDN con: 1) el artículo 13: derecho del niño a la libertad de expresión, derecho que incluirá la libertad de buscar, recibir y difundir informaciones e ideas de todo tipo, sin consideración de fronteras, ya sea oralmente, por escrito o impresas, en forma artística o por cualquier otro medio elegido por el niño; 2) el artículo 6.2: derecho del niño a su desarrollo; 3) el artículo 12: derecho del niño a formarse su propio juicio y a expresar su opinión libremente en los asuntos que le afectan y a que sus opiniones sean debidamente tenidas en cuenta.

Pese a la idea generalizada y comúnmente aceptada de que los niños deben recibir una especial consideración y cuidados por parte de la sociedad, rara vez esto se traduce en su inclusión activa como protagonistas principales de ese proceso. Tampoco en los medios de comunicación están adecuadamente incorporados este tipo de procesos participativos para los niños, a pesar de su derecho (explicitado en varias fuentes) a la publicación y difusión de sus opiniones, tal y como recoge la normativa internacional y la propia Ley española de Protección del Menor, antes citadas.

El Comité de los Derechos del Niño, órgano que supervisa la forma en que los Estados cumplen (o no) sus obligaciones derivadas de la firma de la CDN, consagró el 7 de octubre de 1996 uno de sus debates a la cuestión del niño y los medios de comunicación. Siguiendo un esquema preparado para guiar el debate general, el Comité, compuesto por 18 expertos independientes, expresó la opinión de que, al igual que en el caso de los derechos humanos en general, la prensa y otros medios de comunicación cumplen -o pueden cumplirfunciones esenciales en la promoción y protección de los derechos fundamentales del niño y en la puesta en práctica de los principios y las normas de la CDN. Además, el Comité hizo especial alusión a la posibilidad de que los medios de comunicación ofrecieran a los niños la oportunidad de expresarse. Producto de los debates sobre las diversas cuestiones celebrados tanto en sesión plenaria como en los tres grupos de trabajo formados al efecto, el relator del debate temático sobre infancia y medios de comunicación formuló, entre otras, las siguientes recomendaciones:

1. debería reunirse documentación sobre experiencias prácticas positivas de participación infantil activa en medios de comunicación para promover la idea de medios de comunicación de los niños;

2. debería promoverse el programa de UNICEF "La juventud opina" en la World Wide Web como foro infantil en Internet para el debate internacional sobre cuestiones relevantes para la juventud.

La investigación que aquí planteamos encuentra su justificación, en primer lugar, en la antedicha ausencia de estudios científicos en materia de participación infantil (no meramente simbólica) en medios de comunicación. Son ya bastante numerosos los estudios sobre la influencia que ejercen los medios de comunicación social sobre la infancia y la juventud y también los estudios relativos a los usos que este sector social hace de esos medios, pero no es tan profuso el caudal de investigación sobre el papel de los niños como productores y emisores de mensajes públicos canalizados a través de medios de comunicación. En este sentido, el Programa CAI ha propuesto la presente investigación con un doble objetivo: por una parte, contribuir a paliar ese relativo vacío investigador y, por otro lado, cumplir con la finalidad del propio Programa CAI en la defensa y promoción de los derechos de la infancia, de la aplicación de la CDN y del cumplimiento con las recomendaciones del Comité de los Derechos del Niño a las que aludíamos en el párrafo anterior. Con ello, pretendemos también estimular nuevas líneas de trabajo técnico (y político) a nivel municipal en el ámbito de la participación infantil en medios de comunicación, poniendo a disposición de los promotores de esas líneas documentación útil para 
tal labor de promoción y para el desarrollo de proyectos de participación infantil y juvenil en medios.

\section{MATERIAL Y MÉTODOS}

\subsection{Población}

La población objetivo del estudio han sido los 54 municipios españoles reconocidos por UNICEF España como "Ciudades Amigas de la Infancia" entre la primera convocatoria (año 2004) y la última (año 2011). En concreto: en la primera convocatoria de Reconocimiento de Ciudades Amigas de la Infancia (año 2004), fueron reconocidos los siguientes municipios españoles: Alcázar de San Juan, Alcobendas, Alcorcón, Algete, Andújar, Arganda del Rey, Alzira, Collado Villalba, Coslada, Daimiel, Fuenlabrada, Getafe, Lasarte Oria, Leganés, Lleida, Marmolejo, Mejorada del Campo, Móstoles, Parla, Pinto, Puerto Real, Rivas Vaciamadrid, San Fernando de Henares, San Sebastián de los Reyes, Valdepeñas y Velilla de San Antonio. En la segunda convocatoria de Reconocimiento (año 2006), fueron reconocidos: Barcelona, Granada, Palencia y Umbrete. En la tercera (año 2008), fueron reconocidos: Humanes de Madrid, Madrid, Segovia y Vejer de la Frontera.Y, finalmente, en la cuarta convocatoria (año 2010), fueron reconocidos: Alcalá de Guadaíra, Avilés, Belmonte de Miranda, Cabra, Cáceres, Carrión de los Céspedes, Conil, Cornellá de Llobregat, Laviana, Lora del Río, Málaga, Olivares, Quart de Poblet, San Bartolomé de la Torre, San Cristóbal de Segovia, Siero, Somiedo, Tineo, Vera y Villamayor (5).

\subsection{Metodología}

La presente investigación se ha llevado a cabo siguiendo una doble metodología. Por una parte, se ha realizado un estudio cuantitativo mediante encuesta y, por otra, hemos realizado un estudio cualitativo de algunas iniciativas destacadas de participación infantil y juvenil activa en medios de comunicación identificadas a partir del estudio cuantitativo.

La fase cuantitativa se inició con el diseño y envío de un cuestionario para recabar información sobre las iniciativas de participación infantil en los medios de comunicación de ámbito municipal y sobre los recursos municipales disponibles para estas actividades. La recogida de información se completó mediante entrevistas telefónicas, con las que recabamos información de aquellos municipios que no remitieron el cuestionario o de los que fue necesario completar información.

En una primera instancia, se envió un cuestionario, en marzo de 2011, a los 54 municipios identificados en la población de interés. Del total de municipios consultados, 27 (50\%) respondieron al cuestionario enviado y 27 (50\%) no respondieron. Posteriormente, en septiembre de 2011, se contactó telefónicamente con los 27 municipios que no habían respondido al cuestionario enviado en primera instancia. El cuestionario enviado recoge los indicadores de participación infantil utilizados en el Protocolo de Reconocimiento de Ciudades Amigas de la Infancia (6). Tanto para el envío del cuestionario por correo electrónico como para la consulta telefónica, se utilizó la base de datos de técnicos municipales de la que dispone el Programa CAI. El procedimiento seguido, una vez recabados los datos, consistió en el análisis descriptivo de las iniciativas de participación infantil en medios mediante la frecuencia de respuesta y el cruce de las distintas variables. Los análisis se llevaron a cabo utilizando el programa informático IBM SPSS Statistics versión 19.

Junto al estudio cuantitativo, se ha procedido también a un análisis cualitativo de las iniciativas de participación infantil en medios de comunicación alegadas en los cuestionarios. Para ello, se han seleccionado algunas de ellas, las consideradas por los investigadores como más destacadas. La parte cualitativa ha consistido en visitas personales de los investigadores a los lugares donde se desarrollan esas iniciativas para conocerlas sobre el terreno (7). Asimismo, y dada la notable ausencia de literatura científica al respecto del asunto concreto de nuestro interés, se ha utilizado la documentación presentada por los municipios candidatos al proceso de Reconocimiento 2010-2014 del Programa CAI, las noticias publicadas sobre iniciativas de participación infantil en medios de comunicación y la bibliografía pertinente existente.

\section{RESULTADOS}

La distribución de municipios por criterio de población abarca todo el rango de tamaños, cubriendo desde los municipios de menos de 5.000 habitantes (6\%) hasta los de más de 250.000 habitantes (6\%). El 32\% de los 
municipios cuenta con entre 5.000 y 20.000 habitantes; el $20 \%$, con entre 20.001 y 50.000 habitantes; el $22 \%$, con entre 50.001 y 100.000 habitantes y el $15 \%$, con entre 101.000 y 250.000 habitantes (véase Figura 1).

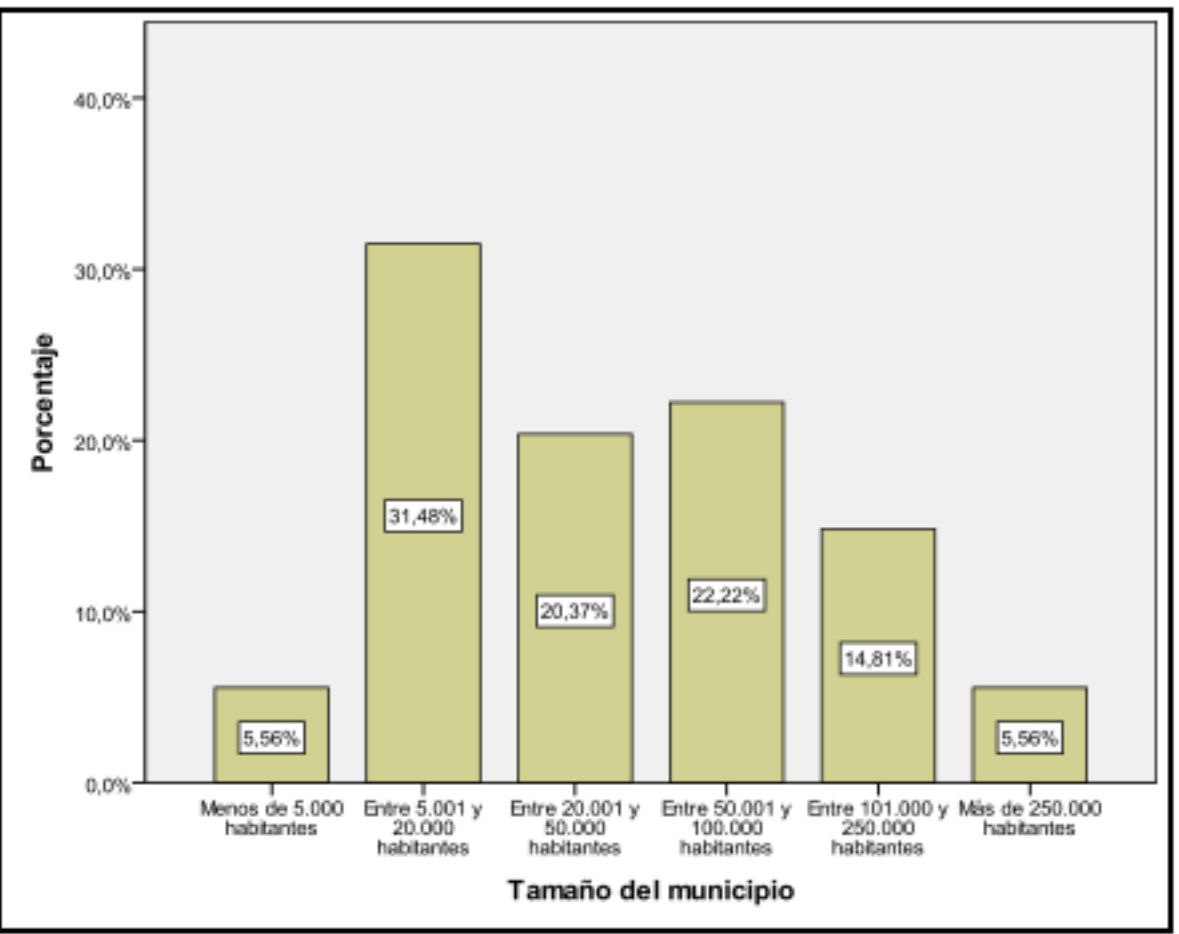

Rango de tamaños poblacionales de los municipios consultados.

De los 54 municipios consultados, 27 (50\%) respondieron inicialmente al cuestionario enviado y 27 (50\%) no respondieron al cuestionario. Con posterioridad, se constató telefónicamente que aquellos que no habían respondido al cuestionario, no disponían de acciones de comunicación dirigida a los niños. De los que contestaron, solo dos municipios no disponían de ningún medio dirigido a los niños. En total, el $46 \%$ de los municipios estudiados dispone de algún medio de comunicación dirigido a la infancia y el $53 \%$ no dispone de medios dirigidos a la infancia (Figura 2).

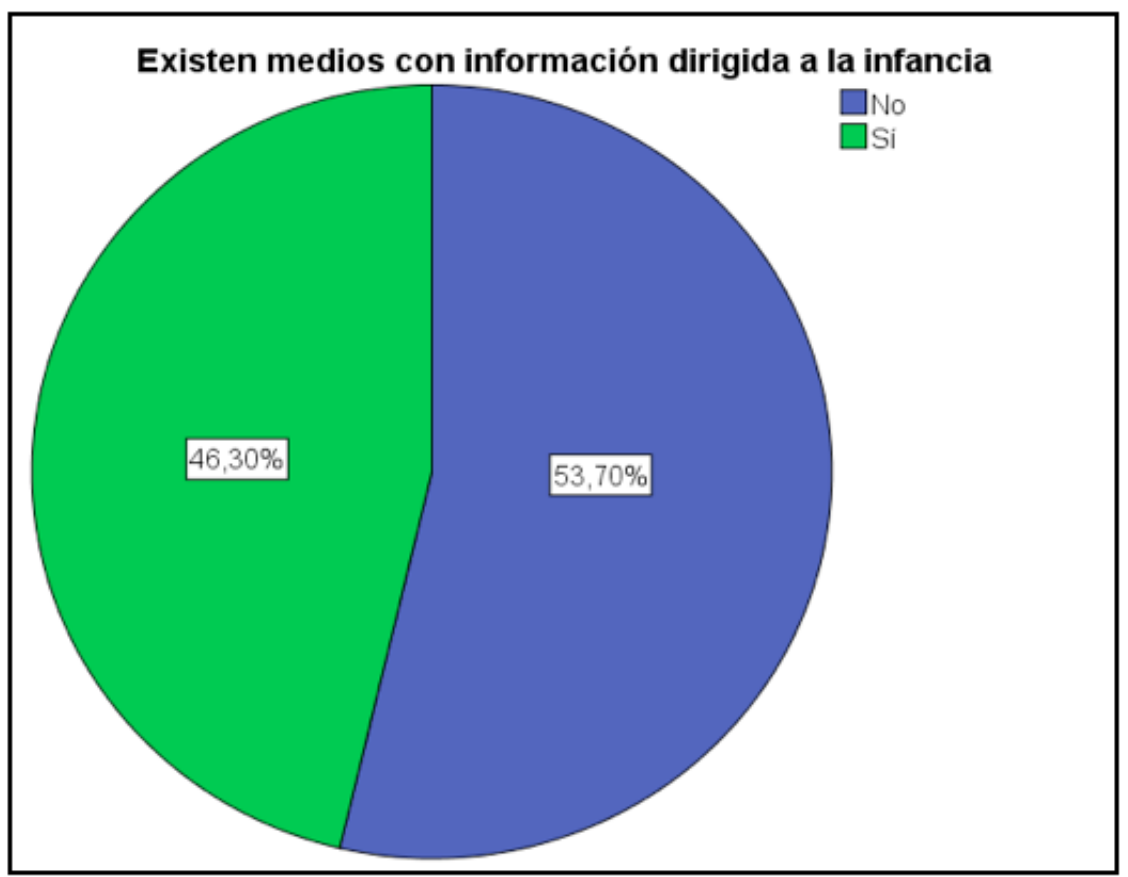

Porcentaje de municipios encuestados en los que existen medios con información dirigida a la infancia.

Como muestra la Figura 3, de los municipios que disponen de medios con información dirigida a niños, un $29 \%$ dispone de secciones en Prensa; un 13\% dispone de este tipo de información en Radio; un 11\%, en TV y un $35 \%$, en alguno de los soportes relacionados con las últimas tecnologías de la información y la comunicación (TICs). De los 25 municipios que disponen de algún medio de comunicación dirigido a los niños, el medio más 
frecuente en el que existe alguna sección dirigida a la infancia es Internet (TICs), disponible en el $76 \%$ de los municipios, seguido de la existencia de alguna sección en Prensa (64\%). En el $28 \%$ de los municipios existen secciones en Radio y en el $24 \%$, en TV.

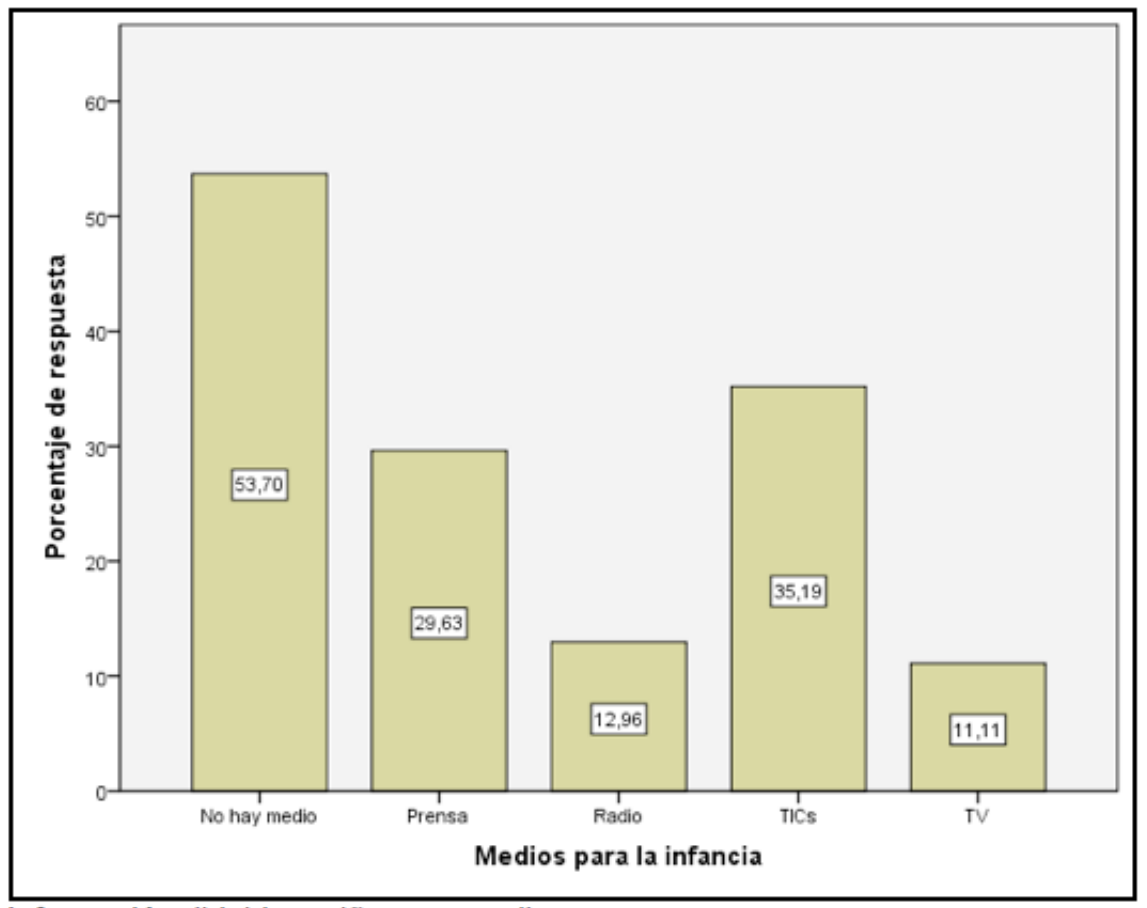

Información dirigida a niños por medio.

Como muestra la Figura 4, el 68\% de los municipios estudiados no dispone de medios en los que participen los niños en alguna medida, frente a un $31 \%$ que sí dispone de ellos.

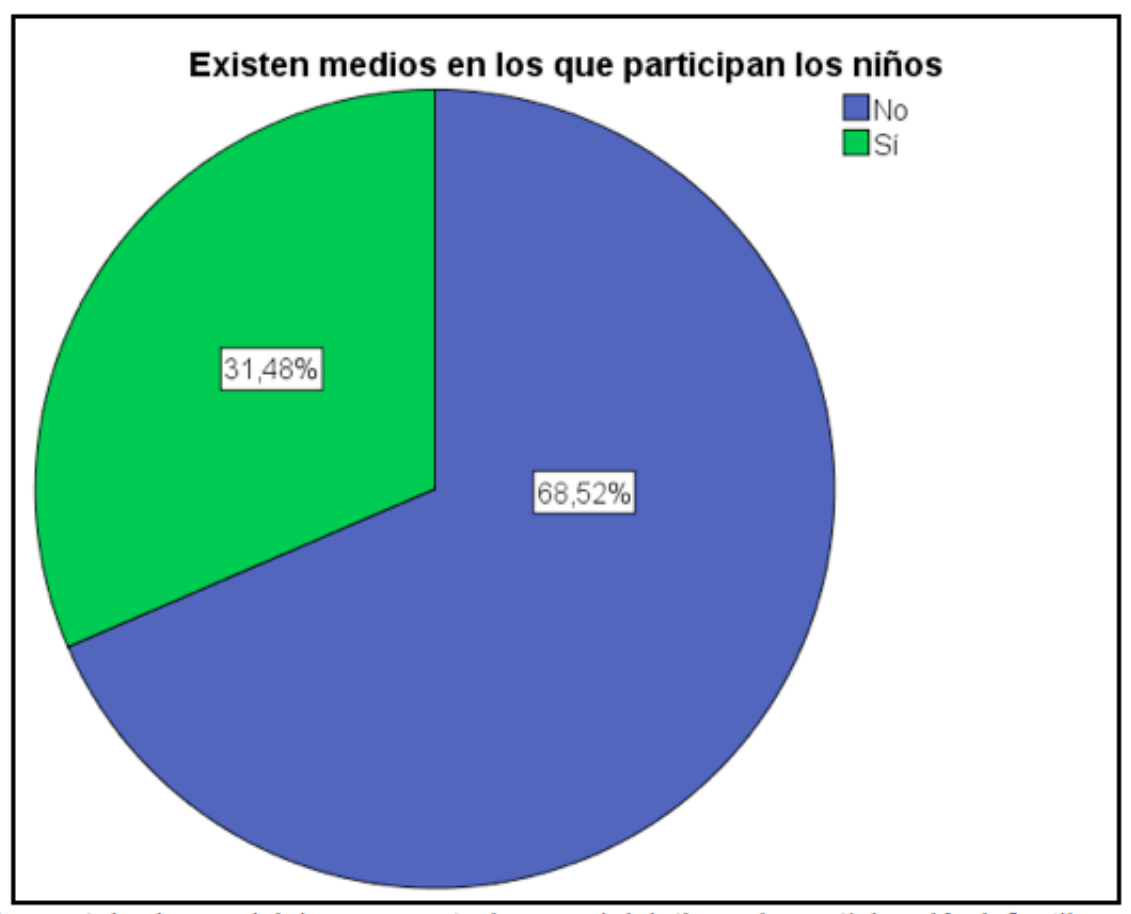

Porcentaje de municipios encuestados con iniciativas de participación infantil en medios.

El medio en el que los niños participan con mayor frecuencia en términos de elaboración de contenidos es Internet (TICs), en el que participan en el $20 \%$ de los casos consultados, seguido de Prensa (17\%), Radio (11\%) y TV (6\%). En el 69\% de los casos, los niños no participan en la elaboración de los contenidos (ver Figura 5). 


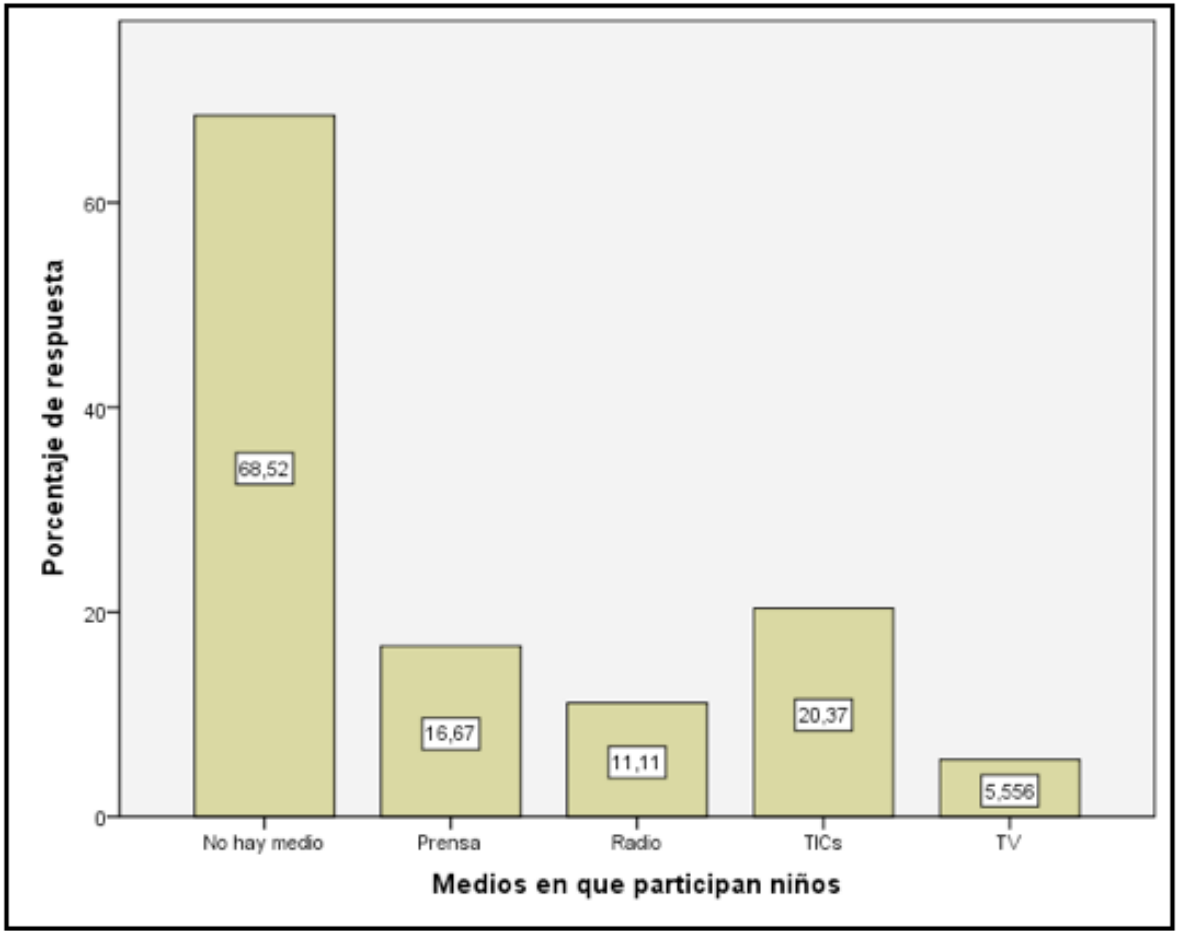

Medios en que participan niños.

Centrándonos en la información medio a medio, cuando se participa en prensa, la mayor parte de las veces lo hacen ambos grupos de edad (11\%), frente a un $6 \%$ en el que solo participan los jóvenes y un $9 \%$ en el que solo participan los niños (8). En el caso de la radio, en el 7\% de los casos participan jóvenes, en el 7\% participan niños y en un $3 \%$ participan tanto niños como jóvenes. Cuando nos centramos en la TV, en el $2 \%$ de los municipios participan niños y jóvenes, en el $4 \%$ participan niños y en el $2 \%$ participan jóvenes. Por último, tal y como muestra la Tabla 1, en las iniciativas de participación en TICs, en el $9 \%$ de los municipios participan niños y jóvenes, en el $4 \%$ participan niños y en el $15 \%$ participan jóvenes.

\begin{tabular}{|l|l|r|r|}
\hline \multicolumn{1}{|c|}{} & Recuento & \multicolumn{1}{c|}{ Resp. } \\
\hline \multirow{5}{*}{ TIC Participa la infancia } & TIC - Participan Ambos & 5 & $9,3 \%$ \\
\cline { 2 - 4 } & TIC - Participan Jóvenes & 8 & $14,8 \%$ \\
\cline { 2 - 4 } & TIC - Participan Niños & 2 & $3,7 \%$ \\
\cline { 2 - 4 } & TIC - No Participan & 43 & $79,6 \%$ \\
\cline { 2 - 4 } & Total & 54 & $107,4 \%$ \\
\hline
\end{tabular}

\section{Participación en TICs por edades.}

La antigüedad de las iniciativas de participación infantil en medios varía entre 2 meses y 180 meses (15 años). Atendiendo al promedio de las antigüedades, las iniciativas más antiguas son las actividades de radio dirigidas a ambos segmentos de edad, con una antigüedad promedio de 96 meses. En general, todas las iniciativas cuentan con una trayectoria de más de año y medio. Agrupando las iniciativas para cubrir todos los tipos de destinatarios (Tabla 2), la antigüedad media de las actividades en prensa se sitúa en los 30 meses, siendo la más reciente de 6 meses atrás y la más antigua de 72 meses atrás (respecto al momento de la realización de la investigación). Las actividades de radio más modernas son de hace 12 meses y las más antiguas de 180 meses, con un valor medio de 26 meses. Las actividades de TV son escasas: la más moderna es de hace 2 meses y la más antigua de hace 48 meses, con una mediana de 45 meses. Por su parte, las iniciativas de TICs más modernas solo cuentan con 3 meses de actividad y las más antiguas son de hace 120 meses, con un valor medio de 28 meses (9).

\begin{tabular}{|c|c|c|c|c|c|c|}
\hline & 1-Diaria & 2-Semanal & 3-Quincenal & 4-Mensual & 5-Trimestral & 6-Anual \\
\hline & $\%$ fila & $\%$ fila & $\%$ fila & $\%$ fila & $\%$ fila & $\%$ fila \\
\hline Frecuencia: Prensa &, $0 \%$ & $16,7 \%$ &, $0 \%$ & $41,7 \%$ & $33,3 \%$ & $8,3 \%$ \\
\hline Frecuencia: Radio &, $0 \%$ & $62,5 \%$ & $12,5 \%$ & $12,5 \%$ & $12,5 \%$ &, $0 \%$ \\
\hline Frecuencia: TV & $75,0 \%$ & $25,0 \%$ &, $0 \%$ &, $0 \%$ &, $0 \%$ &, $0 \%$ \\
\hline Frecuencia: TICs & $62,5 \%$ &, $0 \%$ & $12,5 \%$ & $25,0 \%$ &, $0 \%$ &, $0 \%$ \\
\hline
\end{tabular}

Frecuencia de las iniciativas por medios. 
Respecto a la frecuencia de las iniciativas (Tabla 3), agrupando las respuestas por medios de comunicación y sin tener en cuenta el segmento al que van dirigidos, las actividades de prensa suelen ser mensuales o trimestrales, las de radio son mayoritariamente semanales, las de TV suelen ser diarias o semanales y las TICs son mayoritariamente diarias.

\begin{tabular}{|c|c|c|c|c|c|c|}
\hline & Mediana & Media & $\begin{array}{l}\text { Desviación } \\
\text { típica }\end{array}$ & Mínimo & Máximo & $\mathrm{N}$ válido \\
\hline Antigüedad: Prensa & 30,00 & 30,92 & 17,64 & 6,00 & 72,00 & 13 \\
\hline Antigüedad: Radio & 26,00 & 49,33 & 64,58 & 12,00 & 180,00 & 6 \\
\hline Antigüedad: TV & 45,00 & 31,67 & 25,74 & 2,00 & 48,00 & 3 \\
\hline Antigüedad: TICs & 28,00 & 43,67 & 40,11 & 3,00 & 120,00 & 9 \\
\hline
\end{tabular}

Antigüedad de las iniciativas por medios.

En general, pocos municipios han respondido al número de participantes que colabora en cada una de las iniciativas de comunicación, por lo que es difícil distinguir entre iniciativas. Las TICs y la Prensa parecen ser las que dan pie a un mayor número de participantes (Figura 6). Destaca el hecho de que ningún municipio contesta al número de adultos que participan en las iniciativas de comunicación orientadas en origen a niños y jóvenes.

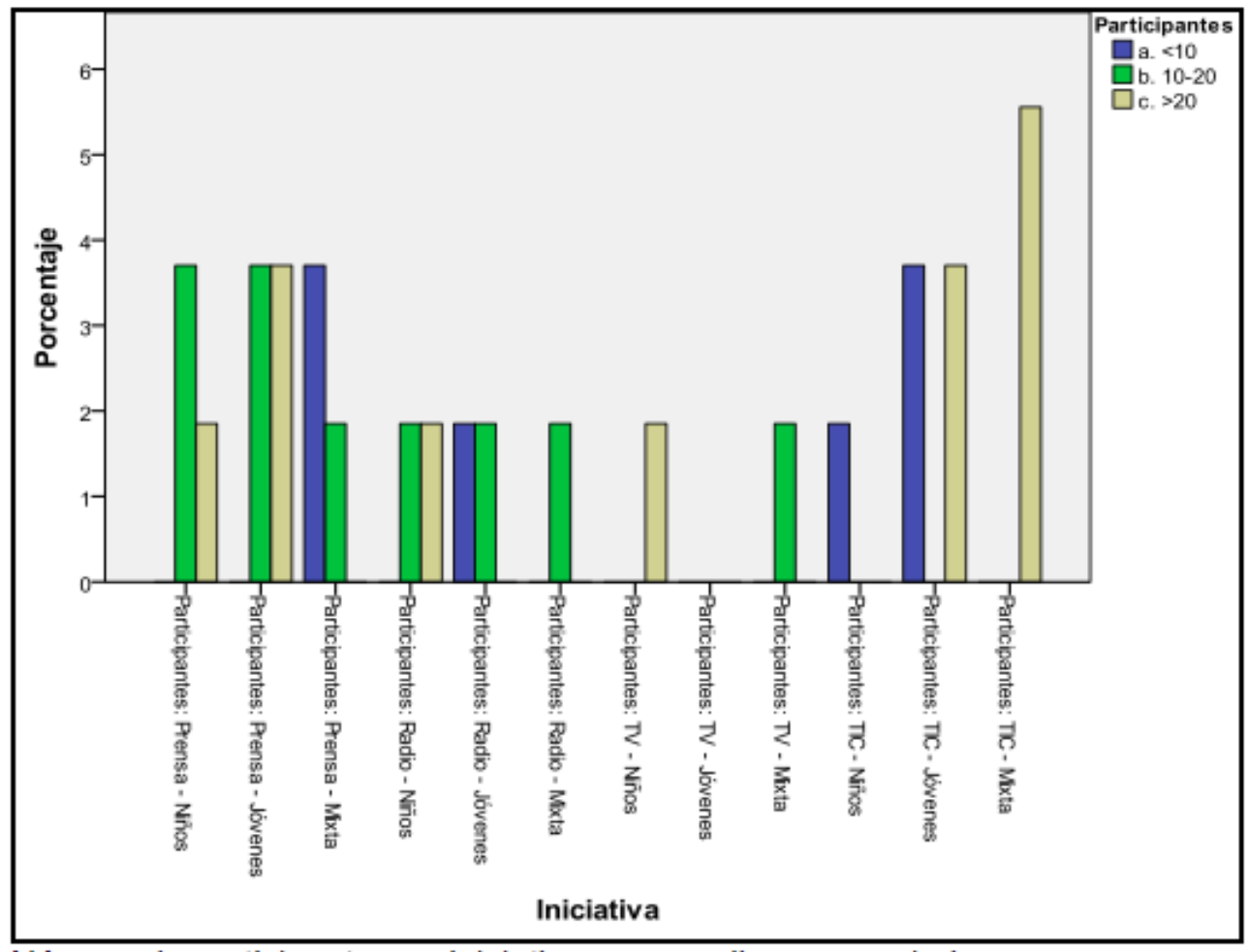

Número de participantes en iniciativas por medios y por edades.

Respecto al modo de financiación de las iniciativas, se ha respondido en general mal a la pregunta sobre los medios de financiación. La financiación más frecuente de las iniciativas es de tipo público. El patrón cambia cuando se trata de la TV, donde parece predominar la financiación mixta (en parte pública y en parte privada). En el caso de las iniciativas de Prensa, el $76 \%$ son de financiación pública; en Radio, el $50 \%$ de las iniciativas son de financiación pública y el $50 \%$ de financiación mixta; en TV, predomina la financiación mixta (67\%) y en el caso de las TICs, el $100 \%$ de las iniciativas son de financiación pública.

\section{DISCUSIÓN}

A la vista de los resultados estadísticos, se perciben escasas iniciativas tanto de medios con información dirigida a niños y jóvenes como de medios participados por estos. No conviene olvidar que el estudio ha sido realizado tomando como universo los 54 municipios españoles reconocidos por UNICEF como "Ciudades Amiga de la Infancia", es decir, municipios que se encuentran a la vanguardia en materia de defensa y promoción de los derechos de la infancia. Es de esperar que si ya en esta muestra se detectan carencias marcadas, una ampliación del universo muestral a los 8.112 municipios españoles arrojaría datos con mayores márgenes aún para la mejora. Por lo tanto, puede concluirse que en España no hay un adecuado desarrollo de los principios contenidos en la CDN y en otras normas respecto a medios de comunicación e infancia ni se han atendido 
convenientemente las recomendaciones del Comité de los Derechos del Niño al respecto.

Las iniciativas de participación infantil en TICs están mayoritariamente protagonizadas por jóvenes de 13 años de edad en adelante y cuentan con escasa participación de niños menores de 13 años. En la era tecnológica en la que nos encontramos inmersos, resultaría conveniente una mayor promoción de la implicación y familiarización de los niños en edades tempranas con las últimas tecnologías.

Las actividades infantiles y juveniles en iniciativas de televisión son escasas. A pesar de la creciente implantación y arraigo social de los nuevos medios (Internet y dispositivos móviles), la televisión continúa siendo el rey de los medios para toda la población, incluida la infantil y adolescente, y sigue ejerciendo una mágica y poderosa atracción y una gran capacidad de influencia.

Aunque ningún municipio contesta al número de adultos que participan en las iniciativas de comunicación orientadas en origen a niños y jóvenes, quizá por ello mismo (y por nuestras observaciones directas en la fase cualitativa de la investigación), se detecta aún un excesivo dirigismo adulto. Los niños deberían gozar de mayores grados de libertad a la hora de proponer y desarrollar los temas de su interés, sin que ello impida el pertinente, necesario y deseable apoyo de los técnicos.

La fuente de financiación de las iniciativas de participación infantil en medios es mayoritariamente de carácter público. Sería deseable una mayor presencia de financiación privada en la promoción y desarrollo de este tipo de iniciativas. Las propias empresas de comunicación, dentro de su compromiso en términos de función social, podrían realizar aportaciones en este sentido sin menoscabo de sus resultados económicos. Existe demasiada variabilidad en la frecuencia de las iniciativas para poder extraer conclusiones. Las iniciativas de prensa tienden a ser de carácter mensual o superior; las iniciativas de radio tienden a ser de carácter semanal o mensual; las de televisión, de carácter diario o semanal y las TICs son de carácter diario o mensual.

Deberían establecerse mecanismos de monitorización y seguimiento de la evolución del mapa de iniciativas (estables) de participación infantil y juvenil en medios de comunicación en España. Los Observatorios de la Infancia y Adolescencia podrían incluir este acometido entre sus labores.

Apenas existen estudios y reflexiones sobre participación infantil real y efectiva en medios de comunicación. Se trata de una línea de investigación, tanto en su vertiente cuantitativa como cualitativa, muy escasamente desarrollada. En este sentido, y siguiendo las recomendaciones hechas por el Comité de los Derechos del Niño ya en 1996, convendría profundizar en la producción de literatura científica (y divulgativa) al respecto para ir consolidando un corpus de documentación sobre buenas (y malas) prácticas en materia de participación infantil y juvenil en medios. Asimismo sería muy beneficioso para la proliferación de este tipo de iniciativas la existencia de guías o documentos marco para la orientación y el asesoramiento de los técnicos interesados en desarrollar este tipo de trabajo con los niños.

\section{REFERENCIAS BIBLIOGRÁFICAS}

BUCHT, C. \& VON FEILITZEN, C. (eds.) (2001): Outlooks on Children and Media. Yearbook 2001. Nordicom. Göteborg (Sweden): The UNESCO International Clearinghouse on Children, Youth and Media. ISBN: 91-8847109-1.

CHARLES, M. \& OROZCO, G. (coords.) (1990). Educación para la recepción. Hacia una lectura crítica de los medios. México: Trillas. ISBN: 968-24-2962-5.

GIROUX, H. (1994). Jóvenes, diferencia y educación posmoderna. En VV.AA. Nuevas perspectivas críticas en educación. Barcelona: Paidós Ibérica, pp. 97-128. ISBN: 84-493-0045-2.

MARTA LAZO, C. (2005). Análisis de la audiencia infantil: de receptores de la televisión a perceptores participantes. Madrid: Universidad Complutense de Madrid. ISBN: 84-669-2481-7.

MARTÍNEZ DE TODA, J. (1998). Metodología evaluativa de la Educación para los medios: su aplicación con un instrumento multidimensional. Tesis doctoral inédita. Roma: Pontificia Universitas Gregoriana. 
MASTERMAN, L. (1994). La enseñanza de los medios de comunicación. Madrid: Ediciones de la Torre. ISBN: 84-7960-055-1.

PÉREZ TORNERO, J. M. (1994). El desafío educativo de la televisión. Para comprender y usar el medio. Barcelona: Paidós. ISBN: 978-84-493-0055-4.

TOFFLER, A. (1980). The third wave. New York: William Morrow. ISBN: 978-0553246988.

(1) Esta investigación ha sido realizada gracias al apoyo económico y técnico del Programa Ciudades Amigas de la Infancia, un Programa de UNICEF España; el Ministerio de Sanidad, Servicios Sociales e Igualdad; la Federación Española de Municipios y Provincias y el Instituto Universitario de Necesidades y Derechos de la Infancia y Adolescencia de la Universidad Autónoma de Madrid.

(2) Ley Orgánica 1/1996 de Protección Jurídica del Menor, de modificación parcial del Código Civil y de la Ley de Enjuiciamiento Civil. Artículo 7-1: "Los menores tienen derecho a participar plenamente en la vida social, cultural, artística y recreativa de su entorno, así como a una incorporación progresiva a la ciudadanía activa. Los poderes públicos promoverán la constitución de órganos de participación de los menores y de las organizaciones sociales de infancia".

(3) Entre los enfoques surgidos desde la línea de investigación cognitiva, encontramos la Teoría biológicocognitiva, de María Montessori; la Teoría de la Gestalt; el Modelo psicolingüista, de Noam Chomsky; la Teoría de la formación del concepto y el aprendizaje verbal, de Eli Saltz, y la Teoría del desarrollo cognitivo, de Jean Piaget.

(4) En relación con el ámbito de la comunicación, en este último nivel podemos señalar, entre otras, las siguientes teorías y líneas de estudio: la teoría de los "efectos limitados" ("teoría ecológica", de Urie Bronfenbrenner); la "teoría de los usos y las gratificaciones", de Elihu Katz y Paul Lazarsfeld, y los "estudios culturales", de Stuart Hall, David Morley, Dorothy Hobson y James Llull.

(5) El Reconocimiento de Ciudades Amigas de la Infancia por parte de UNICEF España y sus socios de Programa (el Ministerio de Sanidad, Servicios Sociales e Igualdad; la Federación Española de Municipios y Provincias y el Instituto Universitario de Necesidades y Derechos de la Infancia y Adolescencia) se produce cada dos años desde 2004. Se trata de un proceso con el que UNICEF reconoce y premia la labor de los Entes Locales españoles en relación con los derechos de la infancia. Para obtener tal reconocimiento, se debe cumplir con el Protocolo correspondiente (disponible en http://www.ciudadesamigas.org/etc/CAI_protocolos_2010.pdf).

(6) El cuestionario puede consultarse en http://www.ciudadesamigas.org/etc/cuestionario.pdf

(7) Existen en España algunos casos destacados de planificación municipal en materia de participación infantil y juvenil en medios de comunicación que conocimos directamente sobre el terreno. Concretamente, la iniciativa Paquenosescuchen, una revista promovida desde el Observatorio de la Infancia y la Adolescencia del Principado de Asturias; el programa de televisión "Un poco de kada", promovido por el Ayuntamiento de Alcázar de San Juan (Ciudad Real) o La Pequeplaza, publicación trimestral impulsada por la Concejalía de Infancia del Ayuntamiento de San Sebastián de los Reyes (Madrid). Se trata de interesantes proyectos sobre los que, junto a otros, es nuestra intención incidir en futuros escritos.

(8) En el cuestionario utilizado, se ha establecido la edad de 12 años para delimitar y discriminar la categoría "niños" (12 años de edad o menos), frente a la categoría "jóvenes" (13 años de edad en adelante).

(9) Dada la gran disparidad entre las antigüedades máximas y mínimas de las iniciativas, estadísticamente resulta más apropiado usar la mediana como valor medio. 


\section{Breve semblanza de los autores}

Joaquín Sotelo González es profesor de Periodismo en la Facultad de Ciencias de la Información de la Universidad Complutense de Madrid, institución por la que se doctoró con Premio Extraordinario en 2005. Ha realizado estancias de investigación y docencia en algunos de los más prestigiosos centros internacionales (Oxford University, European University Institute y University College of Cork) y cuenta con más de setenta publicaciones en distintos soportes, muchas de ellas relacionadas con los derechos de la infancia. Desde 2005, colabora con UNICEF Comité Español en el desarrollo del Programa 'Ciudades Amigas de la Infancia'. Actualmente, forma parte de varios proyectos nacionales de investigación financiados y es productor de contenidos audiovisuales.

Miguel Ángel Ruiz es doctor en Psicología y profesor titular de Técnicas Multivariantes en la Facultad de Psicología de la Universidad Autónoma de Madrid. Realizó su tesis doctoral sobre 'El problema de la estimación del número de factores en los métodos de extracción del Análisis Factorial' (1991) y desarrolla su investigación sobre métodos estadísticos de análisis de datos, especialmente en el campo de las Ciencias Sociales y de la Salud. Ha publicado más de ochenta artículos en revistas nacionales e internacionales sobre técnicas de análisis multivariante y su aplicación, el desarrollo y adaptación de cuestionarios psicométricos y la evaluación de la calidad percibida, en el ámbito sanitario y del consumidor. También ha participado en más de diez libros académicos y manuales sobre análisis de datos y modelos de ecuaciones estructurales. En el campo de la atención a la infancia ha desarrollado investigaciones sobre el estudio de las necesidades de la infancia, el establecimiento de las bases para un Plan Nacional de Infancia, la evaluación de planes de infancia regionales y municipales, el diseño de instrumentos de detección de maltrato infantil, la elaboración de estadísticas de infancia y la valoración de las políticas municipales dirigidas a la infancia. En la actualidad, investiga sobre el desarrollo de sistemas de indicadores de maltrato infantil. También fue el terminólogo de las traducciones al castellano del programa de análisis estadístico SPSS (Chicago, EE.UU.) desde 1994 hasta 2007.

Gregorio Aranda Bricio (Madrid, 1970) es Licenciado en Geografía e Historia por la Universidad Complutense de Madrid, donde también cursó un Máster en Relaciones Internacionales y Comunicación. Desde 2006, es técnico de políticas de infancia en UNICEF Comité Español y coordinador del Programa 'Ciudades Amigas de la Infancia'. Cuenta con experiencia en animación socio-cultural y en el trabajo con menores en sistemas de protección y justicia juvenil en la Administración General, local y autonómica. Ha participado en diversos programas de ayuda al desarrollo, en procesos democráticos y de emergencia en varios países. Ha colaborado en másteres de formación a educadores sociales y cuenta con varias publicaciones relacionadas con los derechos de la infancia.

Francisco Cabezuelo-Lorenzo es profesor del área de Publicidad y Comunicación Audiovisual en la Facultad de Ciencias Sociales, Jurídicas y de la Comunicación del Campus Público 'María Zambrano' de Segovia (Universidad de Valladolid). Es doctor europeo en 'Tecnologías, Estructuras y Tratamientos de la Información' por la Universidad Complutense de Madrid. Es Licenciado en Periodismo (Universidad Complutense de Madrid) y Licenciado en Publicidad y RR.PP. (Universidad Camilo José Cela). Cuenta con un sexenio de investigación reconocido por la CNEAI para el período (2007-2012). Es autor de más de una treintena de artículos en prestigiosas revistas españolas e internacionales y coautor de más de setenta capítulos en obras conjuntas en el campo de las Ciencias de la Comunicación. Ha participado en varios proyectos de investigación de ámbito europeo, nacional y autonómico. Habla inglés, francés e italiano.

Ámbitos. Revista Internacional de Comunicación, n.26, año 2014, tercer trimestre (otoño). 